\title{
A LÓGICA CAPITALISTA NA PRODUÇÃO DO ESPAÇO URBANO E AS SITUAÇÕES DE VULNERABILIDADE SOCIAL NA CIDADE
}

\author{
Capitalist logic in the production of urban space and situations of social vulnerability in the \\ city
}

Judite de Azevedo do Carmo*

*Professora do curso de Licenciatura em Geografia/UNEMAT- Sinop e do Programa de Pós-Graduação em Geografia/UNEMAT- Cáceres. Judite.carmo@unemat.br

\author{
Recebido em 24/07/2018. Aceito para publicação em 01/08/2018. \\ Versão online publicada em 10/08/2018 (http://seer.ufrgs.br/paraonde)
}

\begin{abstract}
Resumo:
O presente texto procura discutir a relação entre a produção capitalista do espaço urbano e a situação de vulnerabilidade social na cidade, tomando como exemplo empírico o caso da ocupação das margens do córrego Jaracatiá em Colíder (MT), tendo como base o materialismo histórico e dialético, com o emprego de técnicas de pesquisa de campo e aplicação de questionário junto aos moradores para identificar seu perfil socioeconômico. Entende-se que há relação entre problemas sociais com os ambientais; entretanto, neste manuscrito deteve-se apenas nas questões sociais por tratar-se de resultados parciais de projeto de pesquisa ainda em andamento. As análises realizadas até o momento demonstram que a população possui baixos níveis de rendimentos e de escolaridade e ao ocupar área de fragilidade ambiental está constantemente exposta à riscos e em situação de vulnerabilidade social, como resultado de sua posição marginal na sociedade capitalista.
\end{abstract}

Palavras-chave: cidade; capital; marginalidade.

\begin{abstract}
The present paper seeks to discuss the relationship between the capitalist production of urban space and the situation of social vulnerability in the city, taking as an empirical example the case of the occupation on the banks of Jaracatiá river in Colíder (Mato Grosso), based on historical and dialectical materialism, using field research techniques and conducting a questionnaire among residents to identify their socioeconomic profile. The relationship between social and environmental problems is known; however, this manuscript deals only with the social issues, as it considers partial results of a research project still in progress. The analyses carried out so far show low levels of income and education among the population, and when it occupies an environmentally fragile area, the population is constantly exposed to risks and situations of social vulnerability, due to its marginal position in capitalist society.
\end{abstract}

Key-words: city; capital; marginality.

\section{Introdução}

A urbanização é um processo social que agrega diversos atores "com objetivos e compromissos diversos", cujas práticas espaciais promovem uma determinada configuração territorial (HARVEY, 2005, p. 170). O mesmo autor, tomando por base a produção capitalista do espaço, argumenta que o processo de produção do espaço urbano "é tanto produto como condição dos processos sociais de transformação em andamento, na fase mais recente do desenvolvimento capitalista" (p. 165).

Lefebvre (1972, p.135) ao discorrer sobre a produção capitalista aponta que ela "acumula as forças capazes de actuarem na transformação da cidade", sendo produzida de forma contraditória e conflitante; e, conforme Carmo (2006) poucos são os cidadãos que usufruem do direito à cidade, ocorrendo; portanto, nos dizeres de Carlos (1992) uma apropriação desigual do espaço urbano por 
parte da população citadina. Essa apropriação desigual reflete na segregação residencial.

À pobreza urbana e à segregação residencial, Souza $(2005$, p. 84) entende que outros problemas podem ser relacionados, como por exemplo, a degradação ambiental, e, esta se faz presente em todas as cidades brasileiras, em diferentes graus. 0 autor alega que há uma interação direta entre problemas sociais e impactos ambientais, justifica que muitos problemas ambientais são causadores de tragédias sociais, ao mesmo tempo em que tem sua origem em problemas sociais, quando não, são agravados por eles.

Compartilhando do pensamento de Souza, defende-se a existência de uma intrínseca relação entre o tipo de ocupação do solo urbano e as condições de vulnerabilidade socioambiental na cidade, estas compreendidas como em Alves (2006) e Alves e Torres (2006) como sobreposição de problemas e riscos sociais e ambientais em uma determinada área, que leva a um agravamento das situações de vulnerabilidade social em razão da exposição ao risco.

Entretanto; este texto, por integrar resultados preliminares de um projeto de pesquisa ainda em andamento, se deterá somente nas situações de vulnerabilidade social, os dados que indicarão o grau de vulnerabilidade ambiental ainda estão sendo levantados, para posterior análise que possibilitará a elucidação da vulnerabilidade socioambiental em Colíder. Para a análise da situação de vulnerabilidade social em Colíder, utilizou-se como universo espacial empírico a ocupação por moradias das margens do córrego Jaracatiá em seu percurso em área urbana (figura 1).

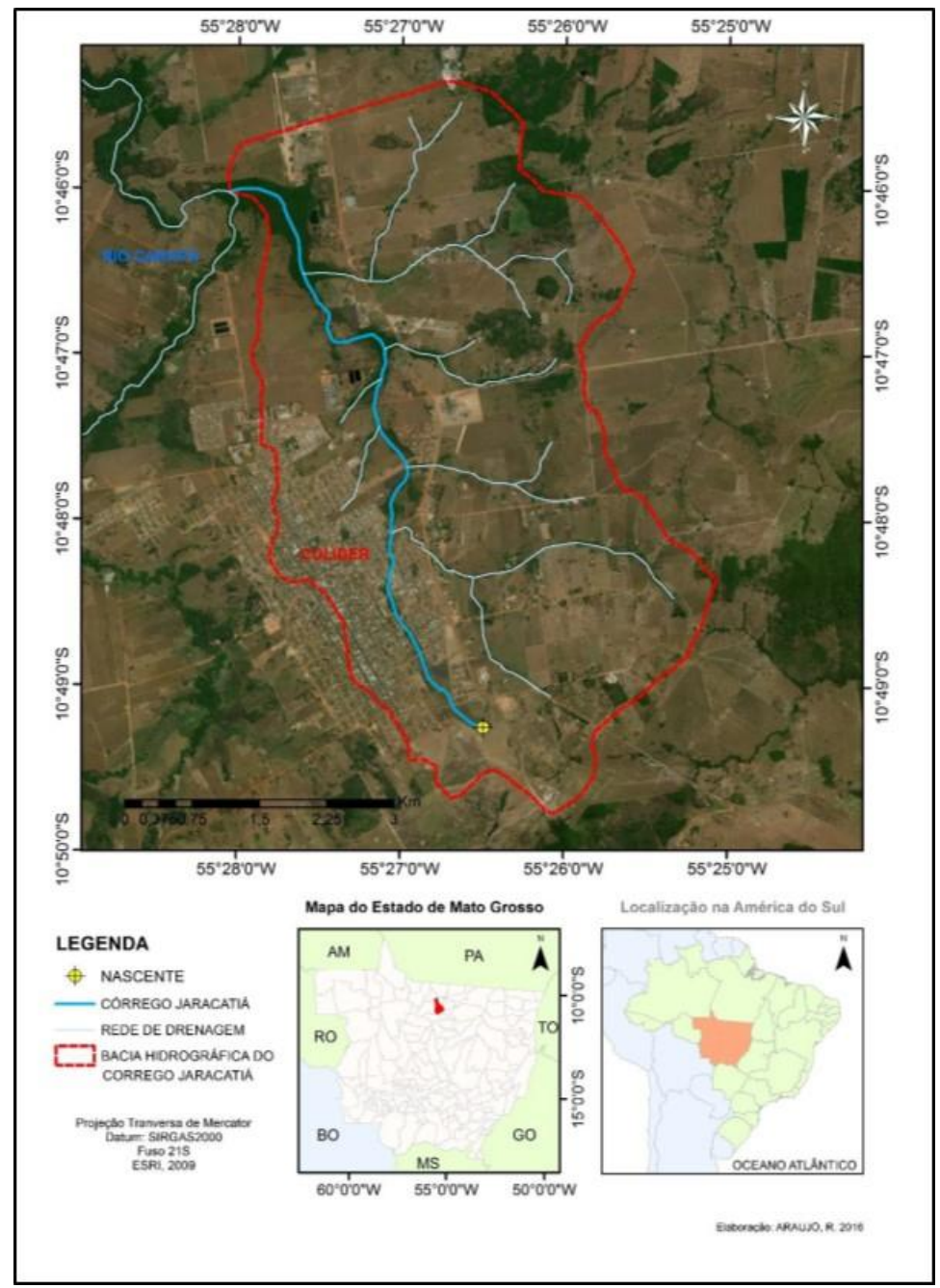

Figura 1- Localização da área de estudo

Fonte: Vieira e Carmo (2017). 
O levantamento dos dados e das informações foi realizado por Gouveia (2017) e Vieira e Carmo (2017) sob a orientação da autora deste texto. A análise realizada está fundamentada no materialismo histórico e dialético, por entender que este possibilita evidenciar as contradições no processo de produção do espaço não somente em sua dimensão concreta espacial, mas também em sua dimensão histórica.

\section{A produção do espaço urbano sob a lógica do capital e a vulnerabilidade social}

Ao apresentar uma crítica sobre a pouca importância dada ao espaço, ao ser tratado como "o morto, o fixo, o não dialético, o imóvel”, em posição contrária ao tempo, Massey $(2008$, p.81) apresenta uma proposição do que é o espaço, "uma multiplicidade discreta, cujos elementos, porém, estão, eles próprios, impregnados de temporalidade”. Esta proposição da autora possibilita entender o espaço como uma simultaneidade dinâmica, impregnado de tempo.

Nesse sentido, o espaço, de acordo com Santos (1986, p.122), "é um verdadeiro campo de forças cuja formação é desigual" e assim, a sua evolução e configuração ocorrem de maneira diferenciada nos diversos lugares. Para Lefebvre (2000, p. 111) o espaço é o "locus" da reprodução social, "não é uma coisa entre as coisas, um produto qualquer entre os produtos [...]. Ele resulta de uma sequência de um conjunto de operações, e não pode se reduzir a um simples objeto".

Em consonância com este referencial, Botelho (2007, p. 21) expõe que "a relação entre o espaço urbano e o modo capitalista de produção é uma via de mão dupla, fazendo parte de uma relação dialética e complexa entre o capitalismo e o espaço".

A produção do espaço urbano em moldes capitalistas produz, de acordo com Lefebvre (2001, p. 138), a "miséria do habitat" e "do habitante". Isto porque, a habitação é tratada como mercadoria, sujeita ao mercado, que possui valor de uso e de troca (CORRÊA, 2003). 0 que significa, como bem especifica Sposito (1988, p. 55), que o acesso à terra urbana é "mediado, pela compra ou aluguel de terrenos com construções ou não".

Ao realizar o debate sobre o planejamento urbano, Soja (1993), destaca que ele é elaborado com vistas ao atendimento, principalmente da classe dominante. Rolnik (2015) também faz alguns apontamentos que evidenciam esta preferência no planejamento urbano, explicando que, no capitalismo financeirizado, a extração de renda se sobrepõe ao capital produtivo, ao passo que as terras urbanas e rurais são tomadas como ativos altamente disputados.

Sob a lógica do capital, conforme Carlos (1994), o espaço urbano é produzido de forma "hierarquizada, dinamizada e segregada", o que favorece o não acesso da população de baixa renda às localidades indicadas para a instalação de habitação. Desta feita, esta população é direcionada a ocupar as áreas periféricas da cidade, não somente aquelas distantes do centro, mas aquelas onde há ausência de infraestrutura de toda ordem, ocorrendo o processo de segregação socioespacial.

A segregação na cidade é planejada, conforme Lefebvre (2001, p. 90), "social e politicamente", pois as estratégias adotadas pela classe dominante, detentora de capital, visam à segregação. Este processo não se limita à divisão espacial urbana entre as classes sociais, ele também procura controlar o espaço por meio de regulamentação e restrição do acesso à terra.

Sobre esta restrição do acesso à terra, Maricato (2001), destaca que ela favorece, especialmente a ocupação, pela população de baixa renda, de áreas públicas ou rejeitadas pelo mercado imobiliário, situadas em localidades, onde se verifica diferentes graus de vulnerabilidade ambiental, como encostas, várzeas, mananciais, de proteção ambiental, dentre outras.

A ocupação dessas localidades de fragilidade ambiental contribui com a sua degradação, influenciando na vida da população ali residente, cuja vulnerabilidade é muito baixa em razão de seu poder econômico. A vulnerabilidade social, conforme o conceito apresentado por Mendes e Tavares (2011, s/p), refere-se à predisposição que um determinado grupo tem de ser afetado, "em termos 
físicos, económicos, políticos ou sociais, no caso de ocorrência de um processo ou acção desestruturante de origem natural ou antrópica".

Marandola Júnior e Hogan (2004) defendem que o termo vulnerabilidade precisa ser analisado simultaneamente com o conceito de risco, isto porque ele aprece nos estudos de risco, primeiramente em sua dimensão ambiental, só posteriormente é que o considera no contexto socioeconômico.

Mendes e Tavares (2011, s/p) explicam que há um consenso entre autores que trabalham com esta temática de que a vulnerabilidade social não é "uma simples consequência da exposição aos perigos", é resultante das "condições de desigualdade social que precedem a ocorrência desses processos e que podem estar relacionados com factores como a pobreza, a idade, o género ou a classe social".

Nesta perspectiva, segundo os autores acima referenciados, "assume-se que a vulnerabilidade social está diretamente ligada ao grau de desenvolvimento econômico, o acesso aos recursos, os modos de vida e os meios de subsistência das pessoas e dos grupos afectados" (s/p). Concluem ainda que a população nesta condição é aquela que se encontra em risco não simplesmente porque está exposta ao perigo, mas como resultado da marginalidade em que vive.

Por entender a necessidade de estudos que relacionem as condições socioeconômicas e de localização da população às situações de vulnerabilidade social, no item a seguir tratar-se-á da ocupação das margens córrego Jaracatiá, evidenciando a vulnerabilidade social em Colíder (MT).

\section{Vulnerabilidade social em Colíder (MT)}

A região onde se localiza o município de Colíder, tem a sua ocupação como consequência da denominada "marcha para o oeste". De acordo com Guimarães e Leme (1997), a expansão da fronteira agrícola na região Centro-Oeste, bem como a construção de Brasília, favoreceu a intensificação do processo de migração para esta nova área, nos anos de 1960 e 1970, especialmente de pessoas de origem sulista.

A aglomeração no espaço, hoje ocupado pelo município de Colíder, iniciou-se no período em que se expandia a BR-163; e, a princípio foi denominada de "gleba Cafezal", somente no ano de 1973 é que foi constituído oficialmente como município por Raimundo Costa Filho (IBGE, 2015). A sua população, segundo a estimativa do IBGE para 2016 era de 32.120 habitantes.

0 acesso à terra no município vai ao encontro dos dizeres de Corrêa (2003) de que a demanda por terras destinadas às moradias depende do surgimento de novas camadas sociais, detentoras de uma "certa renda" que lhes possibilite participar do mercado de terras. Destarte, a terra sendo utilizada como mercadoria, ou seja, sob a influência do capital, segundo Carlos (1992), condiciona a população, sem os rendimentos suficientes para adquiri-la, a procurar áreas periféricas ou irregulares, que por não serem atrativas ao mercado imobiliária, são comercializadas à um valor mais baixo, quando não se estabelecem em áreas públicas ou de preservação permanente.

Verifica-se em Colíder, como acontece em outros municípios brasileiros, que os espaços mais valorizados na cidade, localizados em área central ou nobre, com acesso a todos os serviços urbanos, são ocupados pela população de rendimentos elevados. Em contrapartida, a população de baixa renda localiza-se em áreas de menor prestígio no mercado imobiliário, como as margens do córrego Jaracatiá.

Cardoso (2011) sobre as diferentes formas de produção e apropriação de moradia pelos diversos grupos sociais, especifica que elas são fatores de promoção de desigualdades no espaço urbano, pois o quesito "moradia" é fundamental para a sobrevivência dos indivíduos, aliados ao acesso à saúde, renda e educação.

Dentre as moradias identificadas nas margens do córrego, conseguiu-se analisar amplamente 
treze, porque muitas estavam desocupadas no momento da pesquisa e outras, os moradores não quiseram participar do questionário, demonstrando-se receosos, com medo de represália por parte do poder público, por tratar-se de uma ocupação irregular.

A pesquisa realizada junto à quarenta e duas pessoas, distribuídas nas treze residências mencionadas anteriormente, possibilitou identificar que dentre elas o número de adultos (de 20 a 59 anos) é de 18 indivíduos, enquanto a população jovem (de 0 a 19 anos) atinge o número de sete, nove sujeitos se apresentam na faixa etária composta pelos idosos (60 anos e mais). Este levantamento indica que há uma significativa presença de população economicamente ativa na área estudada, bem como reduzido número de jovens.

Quanto à escolaridade, Gouveia (2017) apresenta que 97\% dos mantenedores das famílias, possuem Ensino Fundamental completo e 3\% Ensino Fundamental incompleto, nenhum dos chefes de família chegou a iniciar o Ensino Médio. A autora ressalta que o índice baixo de escolaridade, evidencia a dificuldade dessa população inserir-se na Educação Formal, o que compromete a sua pretensão à um emprego que lhe proporcione uma renda melhor.

Isto pode ser evidenciado quando se obteve que, a média mensal dos rendimentos dos moradores é de $\mathrm{R} \$ 1.655,00$. Entretanto, destaca-se que esta média estatística não retrata a realidade, pois identificou-se grandes desigualdades neste quesito entre as famílias que ocupam as margens do córrego. Há moradias em que sete integrantes vivem com um salário mínimo, enquanto em outro ponto da ocupação encontra-se família com quatro integrantes que possui ganho mensal acima de três salários.

A situação econômica dessas famílias ocupantes da margem do córrego é refletida em suas moradias, que são simples e pequenas, muitas ainda construídas em madeira, com problemas estruturais sendo destacados no seu apodrecimento, rachaduras, telhados trincados, como evidenciam Vieira e Carmo (2017). As que são de alvenaria, encontram-se em grande parte inacabadas, o que indica a falta de recursos para a conclusão da obra (figura 2).
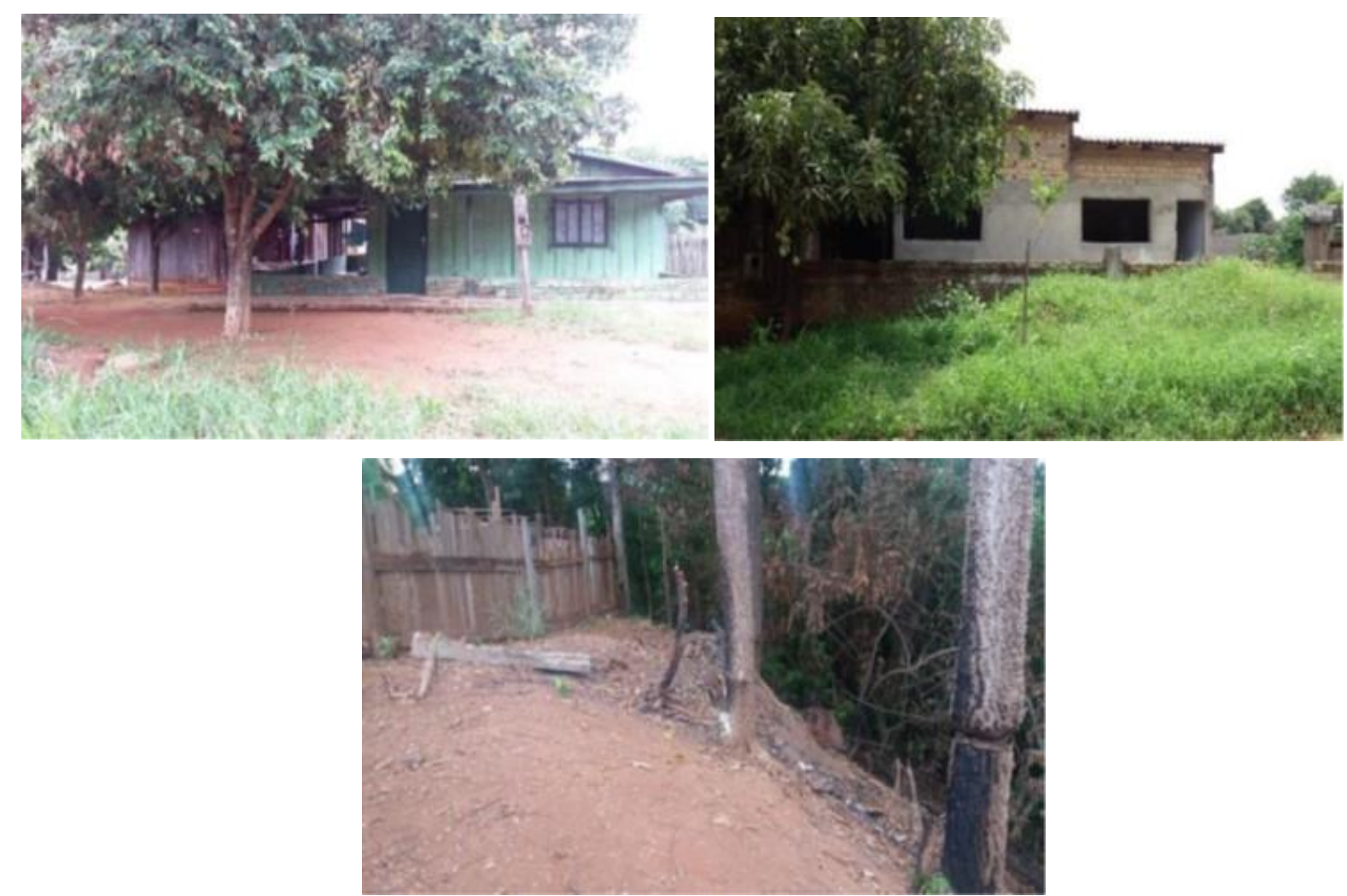

Figura 2- As moradias nas margens do córrego Jaracatiá em Colíder (MT) Fonte: Vieira e Carmo (2017). 
Outro fator que deve ser ressaltado quanto às moradias é a localização de algumas em pontos do córrego que podem ser considerados de risco, como terrenos muito íngremes (figura 2). A localização das moradias nessas áreas de risco pode ter como consequência um desastre que pode colocar em risco a vida dos residentes. 0 estabelecimento de residência em encostas, onde há ausência de vegetação, pode contribuir para que ocorra deslizamento de terra (BUSTAMANTE, 2010).

No que se refere ao acesso aos serviços urbanos, obteve-se que apenas oito residências são servidas com água encanada, as outras cinco possuem o poço artesiano como fonte para o seu abastecimento. De acordo com Razolini e Gunther (2008) a ausência de fontes seguras de água para o consumo da população é um fator que pode agravar as condições de vida dela.

0 acesso à rede de esgoto também é restrito na área, sendo que onze moradias possuem como recurso a fossa séptica; esta, muitas vezes implantada em ponto muito próximo ao recurso hídrico e do poço artesiano usado para o consumo de água, o que pode gerar a contaminação do córrego e um problema sério para a saúde da população residente.

Verificou-se junto aos moradores que apenas duas residências possuem escritura do terreno. Portanto, trata-se de uma área em que a ocupação não está regularizada. Esta condição explica a resistência dos moradores em colaborar com a pesquisa por meio de fornecimento de informação.

A ocupação das margens do córrego Jaracatiá, segundo Vieira e Carmo (2017), ocorreu em tempos distintos, com a construção de residências que datam de pelo menos três décadas e outras ainda recém construídas. Apesar de o processo de ocupação da área por residência ter iniciado logo nos primórdios da constituição do município, o mesmo autor aponta que muitos moradores da localidade aí residem há pouco tempo, variando de dois meses a oito anos.

Outra questão que chama a atenção na área de ocupação é que apesar de não ser regulamentada, observa-se que algumas delas são alugadas, evidenciando o tratamento da terra e da moradia como mercadoria.

O levantamento e análise das condições socioeconômicas e das características habitacionais dos moradores das margens do córrego, demonstram o seu nível baixo de renda e de escolaridade, habitando residências em condições precárias, instaladas em áreas de risco, podendo concluir que esta população se encontra em situação de vulnerabilidade social.

Gouveia (2017) ao tratar da vulnerabilidade e resiliência da população do entorno do córrego em questão, especifica que é evidente a vulnerabilidade desses moradores, em razão de suas condições econômicas; e, consequentemente o seu poder de resiliência é muito baixo. A autora ainda ressalta que esta situação se complica quando se verifica a ineficiência ou mesmo a inexistência de políticas públicas voltadas às pessoas ali residentes.

\section{Considerações Finais}

A produção do espaço urbano sob a lógica capitalista tem como resultado uma cidade segregada, de um lado encontra-se localidades atendidas com todas as benesses urbanas e de outro, áreas completamente abandonadas pelo poder público, muitas vezes sem o atendimento às necessidades básicas da população, como por exemplo, com o fornecimento de água encanada. Esta situação é recorrente não somente nas metrópoles, mas em cidades de diversas dimensões, como em Colíder, uma cidade pequena do norte do Mato Grosso.

A análise dos dados levantados permite afirmar que as famílias residentes às margens do córrego Jaracatiá possuem baixa renda com nível de escolaridade também baixo. Esses fatores aliados à ocupação de áreas de risco, como encostas e área de preservação permanente leva essa população à situação de vulnerabilidade social, com reduzido poder de resiliência. 
Entende-se que as condições socioeconômicas da população analisada tornam impossível a saída desses moradores da localidade em direção à outras áreas da cidade mais propícias e adequadas à habitação. Portanto estão constantemente em situação de risco frente aos possíveis fenômenos naturais como deslizamento de terra, enchentes, assim como à manifestação de doença por contaminação hídrica, por falta de acesso à água encanada e utilização de fossa séptica para o descarte de esgoto.

O cenário urbano que se faz presente na atualidade em Colíder, evidencia um alto grau de vulnerabilidade social, onde as áreas de fragilidade ambiental são ocupadas por população de baixos rendimentos, de forma irregular. Esta situação apresenta um desafio aos gestores, qual seja: criar condições para que se alcance a qualidade social e ambiental na cidade.

\section{Referências}

ALVES, H. P. F. Vulnerabilidade socioambiental na metrópole paulistana: uma análise sociodemográfica das situações de sobreposição espacial de problemas e riscos sociais e ambientais. Revista Brasileira de Estudos de População, São Paulo, v. 23, n. 1, p. 43-59, jan./jun. 2006.

ALVES, H. P. F.; TORRES, H. G. Vulnerabilidade Socioambiental na Cidade de São Paulo: uma análise de famílias e domicílios em situação de pobreza e risco ambiental. Revista São Paulo em Perspectiva, São Paulo, volume 20, número 1 - jan./mar. 2006.

BOTELHO, Adriano. $O$ urbano em fragmentos: a produção do espaço e da moradia pelas práticas do setor imobiliário. São Paulo: Annablume, 2007.

BUSTAMANTE, T. G. C. Impactos da chuva na ocorrência de deslizamento de terra e inundações no estado de São Paulo. 2010. 132 f. Dissertação (Mestrado em Meteorologia) - Instituto nacional de pesquisas espaciais (INPE), São Jose dos Campos, 2010.

CARDOSO, Adauto Lúcio. Desigualdades urbanas e políticas habitacionais. Observatório IPPUR/UFRJFASE.2001.

CARLOS, Ana Fani Alessandri. A cidade. 7º ed. São Paulo: contexto, 1992.

CARLOS, Ana Fani Alessandri. Repensando a Geografia Urbana: uma nova perspectiva se abre, In: CARLOS, Ana Fani Alessandri. Os caminhos da reflexão sobre a cidade e o urbano. São Paulo: EDUSP, 1994, p. 157-198.

CARLOS, Ana Fani Alessandri. Uma leitura sobre a cidade. In: CARLOS, Ana Fani Alessandri. $O$ espaço urbano: novos escritos sobre o urbano. São Paulo: Contexto, 2004.

CARMO, J. A. Dinâmicas sócio-espaciais na cidade de Rio Claro (SP): As Estratégias Econômicas, Políticas e Sociais na Produção do Espaço. 2006. 202 f. Dissertação (Mestrado em Geografia) Instituto de Geociências e Ciências Exatas, Universidade Estadual Paulista "Júlio de Mesquita Filho", Rio Claro. 2006.

CORRÊA, R. L. O espaço urbano. 4º ed. São Paulo: Ática, 2003.

GOUVEIA, Jéssica da Silva. Vulnerabilidade e resiliência da população residente no entorno do córrego Jaracatiá em colíder-MT frente às enchentes. 2017. 47f. Trabalho de Conclusão de Curso (Graduação em Geografia) - Faculdade de Ciências Exatas e Tecnológicas, Universidade do Estado de Mato Grosso, 2017.

GUIMARÃES, Eduardo Nunes; LEME, Heládio José de Campos. Caracterização histórica e configuração espacial da estrutura produtiva do Centro-Oeste. Textos NEPO. Campinas: Núcleos de Estudos de População, UNICAMP, 1997.

HARVEY, D. Condição pós-moderna: uma pesquisa sobre as origens da mudança cultural. Tradução de Adail Ubirajara Sobral e Maria Stela Gonçalves. São Paulo: Loyola, 1989. 
HARVEY, D. A produção capitalista do espaço. Tradução de Carlos Szlak. São Paulo: Anablume, 2005.

HOLNIK, Raquel. Guerra dos lugares: A colonização da terra e da moradia na era das finanças. São Paulo: Boitempo, 2015.

INSTITUTO BRASILEIRO DE GEOGRAFIA E ESTATISTICA - IBGE. Histórico do Município de ColíderMT. Disponível em: <http://biblioteca.ibge.gov.br/visualizacao/dtbs/matogrosso/colider.pdf>. Acesso em: 10 jul. 2016.

LEFEBVRE, H. O pensamento marxista e a cidade. Tradução de Idalina Furtado. Lisboa: Ulisseia, 1972.

LEFEBVRE, H. A produção do espaço. Tradução de Doralice Barros Pereira e Sergio Martins. Paris: Anthropos, 2000.

LEFEBVRE, H. O direito à cidade. Tradução de Eduardo Frias. São Paulo: Centauro, 2001.

MASSEY, Doreen. Pelo espaço: Uma nova política da espacialidade. Tradução de Hilda Pareto Maciel e Rogério Haesbaert. Rio de Janeiro: Bertrand Brasil, 2008.

MARANDOLA JR.; HOGAN, D.J. Vulnerabilidades e riscos: entre geografia e demografia. ENCONTRO Nacional de Estudos Populacionais, 14, Caxambú, 2004.

MARICATO, Ermínia. Brasil, cidades: alternativas para a crise urbana. 2oe edrópolis, RJ: vozes, 2001.

MENDES,José Manuel; TAVARES, Alexandre Oliveira. Risco, vulnerabilidade social e cidadania. Revista Crítica de Ciências Sociais, N. 93, 2011. Disponível em: <http://rccs.revues.org/90>. Acesso em 23 abr. 2017. s/p.

MENDES José Manuel; TAVARES, Alexandre Oliveira; CUNHA, Lúcio; FREIRIA, Susana. A vulnerabilidade social aos perigos naturais e tecnológicos em Portugal. Revista Crítica de Ciências Sociais, n. 93, 2011, Disponível em: <http://rccs.revues.org/90>. Acesso em 23 abr. 2017. s/p.

RAZZOLINI, M.T.P. GUNTHER, W.M.R. Impactos na saúde das deficiências de acesso a água. Saúde e sociedade. Saúde e Sociedade, Revista da USP,Vol.17.no.1, São Paulo, Jan./Mar.2008.

ROLNIK, Raquel. Guerra dos lugares. A colonização da terra e da moradia na era das finanças. São Paulo: Boitempo, 2015.

SANTOS, Milton. Por uma geografia nova: da crítica de geografia a uma geografia crítica. São Paulo: Hucitec, 1986.

SOJA, Edward W. Geografias pós-modernas - a reafirmação do espaço na Teoria Social Crítica. Rio de Janeiro: Jorge Zahar Editor, 1993.

SOUZA, M. L. ABC do desenvolvimento. 2․․ Ed. Rio de Janeiro: Bertrand Brasil, 2005.

SPOSITO, M. E. B. Capitalismo e urbanização. São Paulo: Contexto, 1988. Coleção repensando a geografia.

VIEIRA, W. B. ; CARMO, J. A. Aspectos socioeconomicos e habitacionais da população residente na área de preservação permanente do córrego Jaracatiá em Colider-MT. Geografia (Londrina), v.26, n. 1, p. 779-793, 2017. 